\title{
Mergers and Acquisitions: An Efficiency Evaluation
}

\author{
Paulo Rotela Junior' ${ }^{1}$ Edson de Oliveira Pamplona ${ }^{1}$, Aneirson Francisco da Silva ${ }^{2}$ \\ ${ }^{1}$ Institute of Production Engineering and Management, Federal University of Itajuba, Itajuba, Brazil \\ ${ }^{2}$ Departament of Production, São Paulo State University, Guaratingueta, Brazil \\ Email: paulo.rotela@gmail.com,pamplona@unifei.edu.br, aneirson@yahoo.com.br \\ Received June 7, 2013; revised July 7, 2013; accepted July 15, 2013
}

Copyright (C) 2013 Paulo Rotela Junior et al. This is an open access article distributed under the Creative Commons Attribution License, which permits unrestricted use, distribution, and reproduction in any medium, provided the original work is properly cited.

\begin{abstract}
This article sheds light on how synergies arise through mergers and acquisitions (M\&A). Enterprises go through the process of Mergers and Acquisitions (M\&A) with the goal of improving performance, increasing efficiency and obtaining business synergy. Prior literature suggests that synergies could arise due to taxes, market power or efficiency improvements. This study evaluates the efficiency of M\&A in Brazil among publicly-traded companies. We used models with multiple objectives from Goal Programming and Data Envelopment Analysis (GPDEA), employing accounting indicators as input and output variables, and thus evaluated the emergence of synergy gains. These models allow us to analyze and classify the M\&A according to the efficiency obtained in such processes. Some of the M\&A cases analyzed were mistakenly considered efficient when used traditional models. And, as expected, the GPDEA was proved to be superior to classical models; however it was noticed that few of the cases investigated were proved to be effective. We presented a new application for multi-objective approach that can be used to assess mergers and acquisitions. The dualapplication of GPDEA provided a greater understanding of efficiency generation in synergy creation by means of M\&A.
\end{abstract}

Keywords: Merger and Acquisition; Multiple-Objective Optimization; Goal Programming; Data Envelopment Analysis; Synergy

\section{Introduction}

Mergers and Acquisitions (M\&A) has redefined the corporate managerial environment, evidenced by the everenhanced competitive edge of professional enterprises on today's market.

Theories behind M\&A have supported the concept that the value of the combined companies may rise after coming together. A large part of this justification is associated to the gains contributed to so-called "synergy" [1-4].

According to Kumar and Bansal [5], the task of evaluating M\&A transactions has been one of the greatest difficulties for economic researchers, given that different approaches are taken to identify the effects of M\&As. Moreover, their results are often presented differently.

In a literature review, a large number of M\&A studies were found which focused on countries such as the USA, Canada, and the United Kingdom. However, few studies were found which take a closer look at the Brazilian context. This study aims to address this lack of M\&A studies focusing on Brazil in scientific literature.

Operational Research (OR), specifically Goal Programming (GP) and Data Envelopment Analysis (DEA), may help in evaluating these results. This paper is motivated by the lack of evidence about the synergistic gains via M\&As.

Thus, this article's objective is to utilize GP and DEA models (GPDEA) to evaluate the efficiency of cases of M\&As which have taken place between Brazilian publicly-traded companies.

Specific objective:

- Compare GPDEA models (BBC and CCR) from Bal et al. [6], with classic DEA-BCC and CCR models, proposed by Banker et al. [7] and Charnes et al. [8].

This article analyzes and classifies M\&As according to their obtained levels of efficiency. Upon starting this investigation, it was expected that both pros and cons would be found for M\&As. Another expectation of this study is the confirmations of Bal et al. [6] and Silva et al. [9], who stated that GPDEA models are an important tool to be utilized in efficiency evaluation problems when the quantity of DMUs is not equal to three times the sum of the number of input \& output variables [10].

\section{Mergers \& Acquisitions}

Kummer and Steger [11] state that the main motivation 
for M\&As is the search for growth. While internal growth alternatives sometimes sputter or falter, M\&As are and will continue to be the quickest form of reaching desired growth rates.

M\&As offer a means of acquiring knowledge, technology, stimulating continuous development, reducing risk exposure, reaching economies of scale and scope and increasing innovative capacity [12,13].

According to Kumar [14], M\&As have become the main means of industrial consolidation, which is particularly true for emerging countries.

Mergers and acquisitions generally happen in cyclical patterns, in which periods of less and more pronounced occurrence alternate, driven many times by the need for economic and technological restructuring [3,15-18].

In Brazil, the evolution of M\&As has kept up with global rates, as shown in Figure 1, which presents the total number of F\&As, distributed by year of occurrence. In the period considered between 1994 and 2011, 7391 M\&A processes occurred, with 3376 (45.67\%) involving only Brazilian companies and 4015 (54.33\%) involved cross-border transactions.

According to Phelan [20] and Cigola and Modesti [1], empirical evidence shows that a company's combined value is almost always different than the sum of the values of the companies which went through the M\&A process. When there is a difference between their separate, summed values before the merger or acquisition, and the value of the merged company, it is said that there was synergy - be it positive or negative.

There are many methods for evaluating synergistic gains. The most common is analysis by means of abnormal returns on stocks upon announcement of the transaction according to Healy et al. [21], Linn and Switzer [22], Heron and Lie [23], Gugler et al. [24], Pamplona and Rotela Junior [25] and Wang and Xie [26]. Another means of evaluating M\&As is via accounting indicators, as proposed by Lau et al. [27], Kumar and Bansal [5] and Kumar [14]. Finally, some authors proposed the assessment of the companies involved, both before and after the M\&A, according to Kadapakkam et al. [3].

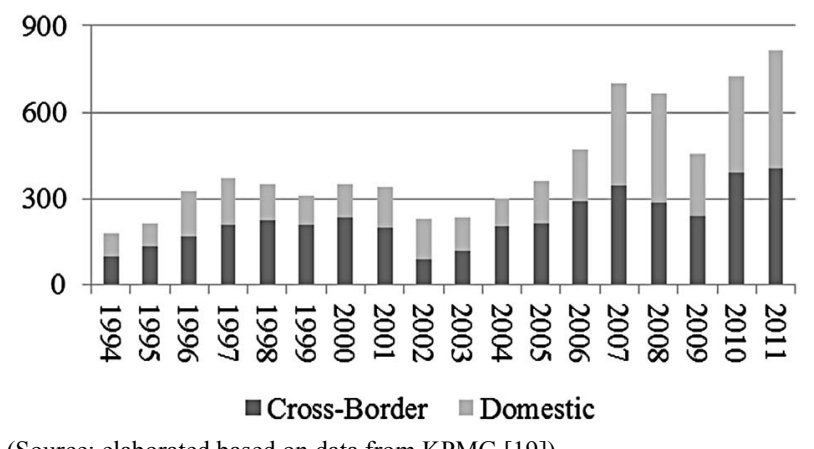

(Source: elaborated based on data from KPMG [19]).

Figure 1. Number of M\&As between 1994 and 2011.
Nonetheless, Kadapakkam et al. [3] question the use of abnormal returns in the synergistic gains evaluation. The authors believe that abnormal returns provide a very condensed measurement of impact, seeing as it doesn't break down the synergy into different types. The evaluation of companies requires a great quantity of data, which makes accounting indicators a good alternative.

\section{Goal Programming and Data Envelopment Analysis}

Charnes and Cooper [28] developed Goal Programming (GP), which, according to Tamiz et al. [29] and Silva et al. [9], is a technique of Multi-Objective Programming which aims to obtain a general solution in order to meet the greatest number of objectives.

According to Silva et al. [9], a wide range of GP models already exist. Among those which deserve to be mentioned are Lexicographic GP (LGP), also known as Preemptive Goal Programming; Weighted GP; and MINMAX GP (MA). These are the most utilized models in available applications, according to Yaghoobi and Tamiz [30] and Silva et al. [9].

Bal et al. [6] point out that Data Envelopment Analysis has stuck out among quantitative modeling techniques in aiding decision making. Charnes et al. [8] touched on this topic for the first time when they developed a new efficiency measurement model for public programs. These classic models are known as DEA: CCR and BBC.

The input and output variable weights for the general DEA model can be obtained based on the solution of the model proposed by Charnes et al. [8], expressed by Equations (1)-(4):

$$
\max E=\sum_{r=1}^{s} u_{r} \cdot y_{r 0} / \sum_{i=1}^{m} v_{i} \cdot x_{i 0}
$$

subject to:

$$
\begin{gathered}
\sum_{r=1}^{s} u_{r} \cdot y_{r j} / \sum_{i=1}^{m} v_{i} \cdot x_{i j} \leq 1, \quad j=1,2, \cdots, n \\
u_{r} \geq 0, \quad r=1,2, \cdots, s . \\
v_{i} \geq 0, \quad i=1,2, \cdots, m .
\end{gathered}
$$

For the expressions above, $j$ represents the DMU index, $j=1, \cdots, n ; r$ is the output index, with $r=1, \cdots, s ; i$ is the input index, $i=1, \cdots, m ; y_{r j}$ is the $r$-th output value for the $j$-th DMU, $x_{i j}$ is the $i$-th input value for the $j$-th DMU $u_{r}$ is the weight associated to the $r$-th output; $v_{i}$ is the weight associated to the $i$-th input; $w_{o}$ is the relative efficiency of $\mathrm{DMU}_{0}$ under analysis; and $y_{r 0}$ and $x_{i o}$ are the technological coefficients in the input and output data matrices for the DMU under analysis.

If $w_{o}=1, \mathrm{DMU}_{0}$ is efficient when compared to the other units considered in the model. In the case that $w_{o}<$ 1 , this DMU is deemed inefficient. This model is not 
linear, as this is a case of Fractionary Programming; however, it may be linearized, as seen in (5)-(9), by means of the model known as CCR, proposed by Charnes et al. [8], or with Constant Returns of Scale.

$$
\max E=\sum_{r=1}^{s} u_{r} \cdot y_{r 0}
$$

subject to:

$$
\begin{gathered}
\sum_{i=1}^{m} v_{i} x_{i o}=1 \\
\sum_{r=1}^{s} u_{r} y_{r 0}-\sum_{i=1}^{m} v_{i} x_{i o} \leq 0 \quad j=1,2, \cdots, n \\
u_{r} \geq 0, \quad r=1,2, \cdots, s . \\
v_{i} \geq 0, \quad i=1,2, \cdots, m .
\end{gathered}
$$

Banker et al. [7] relaxed the assertion of constant returns of scale in CCR models by means of a restriction of convexity, in which the boundary is made up of convex combinations of efficient units. In doing so, variable return of scale can be seen, known as the BCC model, which bears the authors' initials. This is shown in the expressions Equations (10)-(14):

$$
\max E=\sum_{r=1}^{s} u_{r} \cdot y_{r 0}+c_{0}
$$

subject to:

$$
\begin{gathered}
\sum_{i=1}^{m} v_{i} x_{i o}=1 \\
\sum_{r=1}^{s} u_{r} y_{r 0}-\sum_{i=1}^{m} v_{i} x_{i o}+c_{0} \leq 0 \quad j=1,2, \cdots, n \\
u_{r} \geq 0, \quad r=1,2, \cdots, s . \\
v_{i} \geq 0, \quad i=1,2, \cdots, m .
\end{gathered}
$$

It is recommended that the number of DMUs be three times the sum of the total number of variables. Otherwise, according to Cooper et al. [10], traditional DEA methods do not enable suitable data discrimination.

Bal et al. [6] proposed a new DEA model integrated with GP, known as a GPDEA model. For their research, the objective was to analyze efficiency when there are more input and output variables than the number of units for analysis (DMUs).

The GPDEA is derived from multi-objective DEA models, described by Equations (15)-(21) and proposed by Li and Reeves [31]:

$$
\begin{aligned}
& \min d_{o}\left(\text { ou } \max \sum_{r=1}^{s} u_{r} \cdot y_{r 0}\right) \\
& \min W \\
& \min \sum_{j=1}^{n} d_{j}
\end{aligned}
$$

subject to:

$$
\begin{gathered}
\sum_{i=1}^{m} v_{i} x_{i o}=1 \\
\sum_{r=1}^{s} u_{r} y_{r 0}-\sum_{i=1}^{m} v_{i} x_{i o}+d_{j}=0, \quad j=1,2, \cdots, n \\
M-d_{j} \geq 0, \quad j=1,2, \cdots, n \\
u_{r} \geq 0, \quad r=1,2, \cdots, s . \\
v_{i} \geq 0, \quad i=1,2, \cdots, m . \\
d_{j} \geq 0, \quad j=1,2, \cdots, n .
\end{gathered}
$$

In the expressions above, $d_{0}$ is the deviation variable for the $\mathrm{DMU}_{\mathrm{o}} ; d_{j}$ is the deviation variable for the $\mathrm{DMU}_{j}$; $\mathrm{M}$ is the maximum value of the deviation variable ( $\max$ $\left.\left\{d_{j}\right\}\right)$ and $M-d_{j} \geq 0$ defines the maximum deviation $M$ which will not alter the viable region of the decision variables.

Bal et al. [6] associated goals to multiple objective functions from the model by $\mathrm{Li}$ and Reeves [31], and thus, obtained the GPDEA-CCR and GPDEA-BCC models, seen in the expressions (22)-(30) and (31)-(39) below:

\section{GPDEA-CCR:}

$$
\min \left(d_{1}^{-}+d_{1}^{+}+d_{2}^{+}+\sum_{j} d_{3 j}^{-}+\sum_{j} d_{j}\right)
$$

subject to:

$$
\begin{gathered}
\sum_{i=1}^{m} v_{i} x_{i o}+d_{1}^{-}-d_{1}^{+}=1 \\
\sum_{r=1}^{s} u_{r} y_{r 0}+d_{2}^{-}-d_{2}^{+}=1 \\
\sum_{r=1}^{s} u_{r} y_{r 0}-\sum_{i=1}^{m} v_{i} x_{i o}+d_{j}=0 \quad j=1,2, \cdots, n \\
M-d_{j}+d_{3 j}^{-}-d_{3 j}^{+}=0, \quad j=1,2, \cdots, n \\
u_{r} \geq 0, \quad r=1,2, \cdots, s . \\
v_{i} \geq 0, \quad i=1,2, \cdots, m . \\
d_{j} \geq 0, \quad j=1,2, \cdots, n . \\
d_{i} \geq 0, \quad d_{3 j}^{-}, d_{3 j}^{+} \geq 0 .
\end{gathered}
$$

GPDEA-BCC:

$$
\min \left(d_{1}^{-}+d_{1}^{+}+d_{2}^{-}+\sum_{j} d_{3 j}^{-}+\sum_{j} d_{j}\right)
$$

subject to:

$$
\sum_{i=1}^{m} v_{i} x_{i o}+d_{1}^{-}-d_{1}^{+}=1
$$




$$
\begin{gathered}
\sum_{r=1}^{s} u_{r} y_{r 0}+c_{0}+d_{2}^{-}-d_{2}^{+}=1 \\
\sum_{r=1}^{s} u_{r} y_{r 0}-\sum_{i=1}^{m} v_{i} x_{i o}+c_{0}+d_{j}=0 \quad j=1,2, \cdots, n \\
M-d_{j}+d_{3 j}^{-}-d_{3 j}^{+}=0, \quad j=1,2, \cdots, n \\
u_{r} \geq 0, \quad r=1,2, \cdots, s . \\
v_{i} \geq 0, \quad i=1,2, \cdots, m . \\
d_{j} \geq 0, \quad j=1,2, \cdots, n . \\
d_{i} \geq 0, \quad d_{3 j}^{-}, d_{3 j}^{+} \geq 0 .
\end{gathered}
$$

\section{Problem Description and Modeling}

According to Bertrand and Fransoo [32], this research can be classified as applied research, with a descriptive, empirical objective, seeing as the model describes causal relationships which may exist in reality, and thus enables a greater understanding of real processes. The problem is dealt with quantitatively by means of modeling.

With the aim of applying the GPDEA-BCC and GPDEA-CCR models in order to evaluate the efficiency of fusions and acquisitions, the steps proposed by Silva et al. [9] were utilized:

Step (a)-Problem Identification-The problem may be summed up as an efficiency evaluation, by means of economic indicators, of 29 M\&As which occurred during the span of 2000 to 2007 between Brazilian publiclytraded companies.

Step (b) -Data Collection-Eleven accounting indicators, divided into four parameters:

1) Liquidity: General Liquidity (GL) and Current Liquidity (CL);

2) Debt: Debt Profile (DP), level of financial debt (LFD) and participation of Third-Party Capital (TPC);

3) Profitability: Return On Assets (ROA), Return On Equity (ROE) and Earnings Per Share (EPS);

4) Synergy: Gross Margin (GM), Net Margin (NM) and General and Administrative Expenses in Relation to Revenue (GAR).

Historical data were obtained using the database software Economática ${ }^{\circledR}$.

M\&A process efficiency will be analyzed by means of three sets of data: two for companies operating independently, corresponding to the years which preceded the M\&A announcement, and a set of data for the resulting "merged" company upon the enterprises' combination. The resulting average values obtained by the companies under investigation in a period of three years prior to and three years after the business deal announcement are considered.

The year of the announcement was disregarded, given that the effects of the deal make it difficult to compare to other years $[14,21]$. Thus, this article aims to analyze the efficiency of these processes by deeming them either positive or negative for the companies involved, in which inputs (I) are all of the indicators which have minimization objectives, and outputs $(\mathrm{O})$ are the indicators which have maximization objectives. The data were calculated as a relation between the values before and after the M\&A, as shown in Table 1.

Thus, as the input data (I) were utilized in relation to the indicators DP, LFD, TPC and GAR, the best scenarios for each one is to be minimized. Contrarily, for the output data $(\mathrm{O})$, data were utilized in relation to the indicators GL, CL, ROA, ROE, GM, NM and EPS, the best scenarios for each one is to be maximized.

Step (c)-Modeling-The software modules General Algebraic Modeling (GAMS), version 23.6.5 and solver CPLEX, version 12.2.1, were utilized.

Step (d)-Model Solution-Analysis was performed on all of the variables using classic DEA models (BCC and CCR), as well as by Multi-Objective DEA methods (GPDEA-BCC and GPDEA-CCR). Results are presented in Table 2. The super efficiency for the classic models is also presented, in which the efficiency values for the DEA (BCC and CCR) models extrapolate the value of 1, thus enabling them to be classified in accordance with the efficiency evaluation.

In Table 2 it can be observed that 12 efficient DMUs were identified using the BCC method, which represents roughly $41 \%$ of the sample. It can be asserted that the BCC model does not discriminate well between the DMUs. Regarding super efficiency (S. Ef.), it can be seen that DMU16 presents the greatest efficiency, followed by DMU 19.

When analyzing the models obtained with the CCR model, 10 DMUs were identified as efficient, which represents around roughly $34 \%$ of the sample. Due to the fact that companies utilized different types of technology and performed in different economic segments (thus characterizing a scenario of variable return of scale), the results from the classic CCR model are chosen. Similar to the BCC model, the S. Ef. Identifies DMU16 as the most efficient, followed by DMU19.

Table 2 also encompasses the analyses done for the multi-objective DEA, GPDEA models. In the results obtained with the GPDEA-BCC and GPDEA-CCR, it can be observed that only four M\&A cases were considered efficient DMUs. This corresponds to roughly $14 \%$ of the total evaluated, represented by the DMUs 16, 19, 2 and 20 .

Through this study, the assertion from Cooper et al. [10] that when one does not satisfy the rules for the number of DMUs to be three times greater in relation to the sum of the number of variables, application of GPDEA 
Table 1. Matrix of inputs and outputs.

\begin{tabular}{|c|c|c|c|c|c|c|c|c|c|c|c|}
\hline DMU & GL & $\mathrm{CL}$ & $\mathrm{DP}$ & LFD & TPC & ROA & ROE & EPS & GM & $\mathrm{NM}$ & GAR \\
\hline- & $O$ & $O$ & $I$ & $I$ & $I$ & $O$ & $O$ & $O$ & $O$ & $O$ & $I$ \\
\hline 1 & 1.04 & 0.70 & 0.88 & 1.14 & 1.59 & 0.88 & 1.02 & 0.85 & 0.91 & 1.27 & 1.11 \\
\hline 2 & 1.16 & 1.48 & 0.71 & 0.93 & 1.29 & 2.80 & 3.40 & 6.20 & 1.06 & 2.02 & 1.11 \\
\hline 3 & 0.96 & 0.66 & 1.19 & 1.43 & 1.73 & 2.22 & 1.13 & 3.39 & 0.81 & 1.72 & 1.13 \\
\hline 4 & 0.94 & 0.54 & 0.95 & 1.38 & 1.85 & 1.19 & 1.81 & 0.29 & 0.74 & 1.06 & 1.24 \\
\hline 5 & 1.42 & 1.05 & 0.84 & 0.91 & 0.84 & 0.60 & 0.42 & 0.49 & 0.93 & 0.57 & 2.11 \\
\hline 6 & 0.84 & 1.21 & 0.79 & 0.79 & 0.71 & 2.00 & 2.02 & 3.35 & 1.04 & 1.26 & 0.77 \\
\hline 7 & 1.21 & 1.28 & 1.10 & 1.06 & 0.57 & 0.59 & 0.30 & 1.05 & 1.54 & 0.48 & 1.27 \\
\hline 8 & 1.08 & 1.24 & 0.73 & 0.74 & 0.64 & 1.72 & 1.70 & 4.05 & 1.25 & 2.37 & 1.03 \\
\hline 9 & 0.93 & 0.98 & 1.29 & 1.39 & 0.58 & 0.40 & 0.24 & 1.17 & 0.87 & 0.26 & 0.64 \\
\hline 10 & 0.72 & 0.69 & 1.16 & 1.38 & 0.60 & 0.55 & 0.49 & 1.89 & 0.94 & 0.51 & 0.82 \\
\hline 11 & 1.14 & 1.03 & 0.85 & 0.60 & 0.26 & 1.36 & 1.11 & 4.93 & 0.70 & 1.06 & 0.65 \\
\hline 12 & 0.93 & 1.19 & 1.09 & 0.98 & 0.61 & 2.72 & 2.05 & 2.60 & 1.41 & 2.57 & 0.99 \\
\hline 13 & 0.53 & 0.70 & 0.86 & 1.20 & 2.19 & 0.19 & 0.22 & 0.46 & 1.01 & 0.16 & 1.17 \\
\hline 14 & 1.18 & 1.23 & 0.92 & 0.61 & 2.54 & 0.11 & 0.76 & 0.77 & 0.92 & 0.28 & 0.28 \\
\hline 15 & 1.19 & 1.09 & 0.89 & 1.09 & 1.93 & 1.24 & 1.84 & 4.09 & 0.78 & 1.40 & 1.25 \\
\hline 16 & 1.26 & 2.36 & 0.64 & 0.36 & 0.09 & 0.24 & 0.03 & 0.06 & 1.03 & 0.22 & 0.61 \\
\hline 17 & 0.96 & 0.87 & 1.07 & 1.07 & 0.67 & 0.09 & 0.10 & 0.07 & 0.95 & 0.07 & 1.05 \\
\hline 18 & 0.66 & 1.57 & 0.45 & 0.43 & 0.83 & 0.56 & 0.50 & 3.85 & 1.00 & 1.06 & 0.75 \\
\hline 19 & 1.25 & 1.33 & 0.90 & 0.87 & 0.75 & 1.67 & 5.98 & 5.55 & 1.56 & 4.49 & 0.83 \\
\hline 20 & 0.73 & 1.10 & 0.43 & 0.37 & 0.34 & 0.28 & 0.39 & 0.31 & 1.26 & 0.16 & 0.29 \\
\hline 21 & 0.38 & 0.39 & 1.11 & 1.49 & 2.13 & 1.12 & 1.30 & 3.45 & 0.86 & 0.80 & 1.15 \\
\hline 22 & 0.48 & 0.56 & 1.07 & 1.21 & 1.10 & 0.74 & 0.82 & 2.79 & 1.06 & 0.32 & 0.51 \\
\hline 23 & 0.90 & 1.06 & 0.93 & 0.94 & 1.87 & 0.43 & 0.59 & 1.90 & 1.00 & 0.35 & 1.44 \\
\hline 24 & 0.68 & 0.81 & 0.58 & 0.53 & 0.43 & 0.77 & 0.77 & 1.30 & 0.70 & 0.79 & 0.57 \\
\hline 25 & 0.75 & 0.82 & 0.87 & 1.04 & 1.16 & 0.62 & 0.53 & 0.34 & 0.57 & 0.39 & 0.50 \\
\hline 26 & 1.13 & 1.01 & 0.89 & 0.57 & 0.24 & 0.70 & 0.27 & 1.62 & 0.91 & 0.63 & 0.74 \\
\hline 27 & 0.63 & 0.68 & 0.59 & 0.56 & 0.60 & 0.94 & 1.05 & 1.47 & 0.69 & 1.15 & 0.66 \\
\hline 28 & 1.00 & 1.12 & 0.81 & 0.70 & 0.84 & 0.18 & 0.12 & 0.38 & 1.02 & 0.34 & 0.52 \\
\hline 29 & 1.39 & 1.36 & 0.93 & 0.85 & 1.14 & 0.87 & 0.67 & 1.02 & 1.10 & 1.01 & 0.77 \\
\hline
\end{tabular}

Table 2. Results obtained during model application.

\begin{tabular}{|c|c|c|c|c|c|c|}
\hline & BCC & S. Ef. BCC & CCR & S. Ef. CCR & GPDEA-BCC & GPDEA-CCR \\
\hline DMU1 & 0.71 & 0.71 & 0.68 & 0.68 & 0.57 & 0.63 \\
\hline DMU2 & 1.00 & 2.07 & 1.00 & 1.68 & 1.00 & 1.00 \\
\hline DMU3 & 0.76 & 0.76 & 0.76 & 0.76 & 0.40 & 0.60 \\
\hline DMU4 & 0.60 & 0.60 & 0.58 & 0.58 & 0.42 & 0.55 \\
\hline DMU5 & 1.00 & 0.94 & 0.89 & 0.89 & 0.85 & 0.57 \\
\hline DMU6 & 1.00 & 1.06 & 1.00 & 1.05 & 0.61 & 0.79 \\
\hline DMU7 & 1.00 & 0.96 & 0.66 & 0.66 & 0.75 & 0.55 \\
\hline DMU9 & 0.66 & 0.65 & 0.64 & 0.64 & 0.31 & 0.47 \\
\hline DMU10 & 0.52 & 0.52 & 0.47 & 0.47 & 0.59 & 0.90 \\
\hline DMU11 & 1.00 & 2.59 & 1.00 & 2.58 & 0.59 & 0.90 \\
\hline DMU12 & 1.00 & 1.84 & 1.00 & 1.28 & 0.65 & 0.72 \\
\hline DMU13 & 0.51 & 0.51 & 0.41 & 0.41 & 0.25 & 0.28 \\
\hline DMU14 & 1.00 & 2.07 & 1.00 & 1.70 & 0.60 & 0.59 \\
\hline DMU15 & 0.77 & 0.77 & 0.77 & 0.77 & 0.62 & 0.69 \\
\hline DMU17 & 0.49 & 0.49 & 0.47 & 0.47 & 0.40 & 0.44 \\
\hline DMU18 & 1.00 & 1.56 & 1.00 & 1.55 & 0.67 & 0.70 \\
\hline DMU19 & 1.00 & 3.73 & 1.00 & 2.78 & 1.00 & 1.00 \\
\hline DMU20 & 1.00 & 2.27 & 1.00 & 2.24 & 1.00 & 1.00 \\
\hline DMU21 & 0.55 & 0.55 & 0.46 & 0.46 & 0.10 & 0.27 \\
\hline DMU22 & 0.97 & 0.98 & 0.93 & 0.93 & 0.22 & 0.36 \\
\hline DMU23 & 0.56 & 0.56 & 0.55 & 0.55 & 0.47 & 0.42 \\
\hline DMU24 & 0.95 & 0.95 & 0.75 & 0.75 & 0.36 & 0.73 \\
\hline DMU25 & 0.77 & 0.77 & 0.70 & 0.70 & 0.23 & 0.59 \\
\hline DMU26 & 0.81 & 0.81 & 0.80 & 0.80 & 0.61 & 0.74 \\
\hline DMU27 & 0.95 & 0.95 & 0.73 & 0.73 & 0.31 & 0.68 \\
\hline DMU28 & 0.75 & 0.75 & 0.75 & 0.75 & 0.60 & 0.71 \\
\hline DMU29 & 0.91 & 0.91 & 0.89 & 0.89 & 0.83 & 0.89 \\
\hline
\end{tabular}


is a viable solution which does not add a lot of complexity to final analysis.

It can be observed that DMU16 was classified in first place for the classic DEA models as well as the BCC and CCR models. However, when DMU11 is considered, it is classified in third place in Super efficiency of the classic models and considered inefficient in GPDEA models.

Figure 2 presents a summarized form of the efficiency identified in each of the models in order to compare the results obtained in the classic DEA-BCC and CCR models with the GPDEA models.

Step (e) - Validation-The information obtained in this study was validated with the help of specialists in area of economic evaluation by comparing the analyses carried out against results from the same sample using different methods, while considering the Brazilian economic scenario. It was evident that GPDEA is more suitable for dealing with classic DEA-BCC and CCR models.

\section{Conclusions}

As evidenced, there are few articles which investigated the efficiency of M\&A processes carried out in Brazil, and even less which use DEA and GPDEA models in order to do so.

The application of the GPDEA model was proved to be strong for use with multi-objective models, seeing that it enabled a great discrimination of DMUs. As expected, the GPDEA approach was proved to be superior to classic models.

As proof of this, some M\&A cases analyzed were erroneously considered efficient when traditional methods were used. However, only four of these were considered efficient when GPDEA models were employed.

The GPDEA-BCC model is the most suited for these types of analysis due to the fact that the companies utilized different kinds of technology and belonged to different segments, which characterizes a variable return of scale.

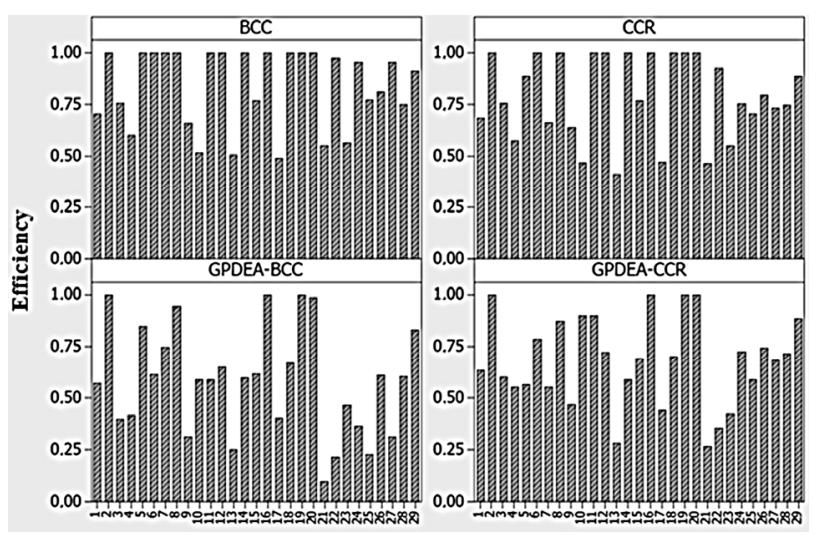

Figure 2. Comparison of classic DEA models with GPDEA models.
Through analysis of the results, it can be asserted that M\&As in Brazil between 2000 and 2007, involving publicly-traded companies were very rarely efficient and had diminished synergistic gains.

As far as future research opportunities, it is suggested that GPDEA models are utilized in combination with stochastic models to evaluate uncertainty.

\section{Acknowledgements}

The authors would like to express their gratitude to the Brazilian agencies CNPq (National Counsel of Technological and Scientific Development), CAPES (Post-Graduate Federal Agency), and FAPEMIG (Foundation for the Promotion of Science of the State of Minas Gerais), which have been supporting the efforts for the development of this work in different ways and periods.

\section{REFERENCES}

[1] M. Cigola and P. Modesti, "A Note on Mergers and Acquisitions," Managerial Finance, Vol. 34, No. 4, 2008, pp. 221-238. http://dx.doi.org/10.1108/03074350810849260

[2] M. Uddin and A. Boateng, "An Analysis of Short-Run Performance of Cross-Border Mergers and Acquisitions: Evidence from the UK Acquiring Firms," Review of Accounting and Finance, Vol. 8, No. 4, 2009, pp. 431-453. http://dx.doi.org/10.1108/14757700911006967

[3] P. Kadapakkam, S. Krishnamurthy and E. Devos, "How Do Mergers Create Value? A Comparison of Taxes, Market Power, Efficiency Improvements as Explanation for Synergies," Review of Financial Studies, Vol. 22, No. 3, 2009, pp. 1179-1211.

[4] K. Nogeste, "Understanding Mergers and Acquisitions (M\&A) from a Program Management Perspective," International Journal of Managing Projects in Business, Vol. 3, No. 1, 2010, pp. 111-138.

[5] S. Kumar and L. Bansal, "The Impact of Mergers and Acquisitions on Performance in India," Management Decision, Vol. 46, No. 10, pp. 1531-1543.

[6] H. Bal, H. Örkcü and S. Celebioglu, "Improving the Discrimination Power and Weights Dispersion in the Data Envelopment Analysis," Computers \& Industrial Engineering, Vol. 37, No. 1, 2010, pp. 99-107.

[7] R. D. Banker, A. Charnes and W. W. Cooper, "Some Models for Estimating Technical and Scale Inefficiencies in Data Envelopment Analysis," Management Science, Vol. 30, No. 9, 1984, pp. 1078-1092. http://dx.doi.org/10.1287/mnsc.30.9.1078

[8] A. Charnes, W. W. Cooper and E. Rhodes, "Measuring the Efficiency of Decision Making Units," European Journal of Operational Research, Vol. 2, No. 6, 1978, pp. 429-444.

http://dx.doi.org/10.1016/0377-2217(78)90138-8

[9] A. F. Silva, F. A. Marins and J. A. Montevechi, "MultiChoice Mixed Integer Goal Programming Optimization for Real Problems in a Sugar and Ethanol Milling Company," Applied Mathematical Modeling, Vol. 37, No. 9, 
2013, pp. 6164-6162.

http://dx.doi.org/10.1016/j.apm.2012.12.022

[10] W. W. Cooper, L. M. Seiford and K. Tone, "Data Envelopment Analysis: A Comprehensive Text with Models, Application, References and DEA-Solver Software," 2nd Edition, Springer Science + Business, New York, 2007.

[11] C. Kummer and U. Steger, "Why Mergers and Acquisitions (M\&A) Waves Reoccur: The Vicious Circle from Pressure to Failure," Strategic Management Review, Vol. 24, No. 2, 2008, pp. 44-63.

[12] G. Lodorfos and A. Boateng, "The Role of Culture in the Merger and Acquisition Process: Evidence from the European Chemical Industry," Management Decision, Vol. 44, No. 10, 2006, pp. 1405-1421. http://dx.doi.org/10.1108/00251740610715722

[13] K. Christensen, "Losing Innovativeness the Challenge of Being Acquired," Management Decision, Vol. 44, No. 9, 2006, pp. 1161-1182. http://dx.doi.org/10.1108/00251740610707668

[14] S. Kumar, "Post-Merger Corporate Performance: An Indian Perspective," Management Research, Vol. 32, No. 2, 2009, pp. 145-157.

[15] M. Gort, "An Economic Disturbance Theory of Mergers," Quarterly Journal of Economics, Vol. 83, No. 4, 1969, pp. 624-642.

[16] M. Jensen, "The Modern Industrial Revolution, Exit and the Failure of Internal Control Systems," Journal of Finance, Vol. 48, No. 3, 1993, pp. 831-880.

[17] M. Mitchell and J. Mulherin, "The Impact of Industry Shocks on Takeover and Restructuring Activity," Journal of Financial Economics, Vol. 41, No. 2, 1996, pp. 193229.

[18] J. Harford, "What Drives Merger Waves," Journal of Financial Economics, Vol. 77, No. 3, 2005, pp. 529-560.

[19] "KPMG Corporate Finance, Mergers and Acquisitions Research," 2013. http://www.kpmg.com/BR/PT/Estudos_Analises/artigosep ublicacoes/Documents/Fusoes\%20e\%20Aquisicoes/2012/ FA-3-trim-2012.pdf

[20] S. Phelan, "Exposing the Illusion of Confidence in Financial Analysis," Management Decision, Vol. 35, No. 2, 1997, pp. 162-168. http://dx.doi.org/10.1108/00251749710160322

[21] P. M. Healy, K. Palepu and R. S. Ruback, "Does Corporate Performance Improve after Mergers?" Journal of Financial and Quantitative Analysis, Vol. 37, No. 1, 1992, pp. 135-175.
[22] S. Linn and J. Switzer, "Are Cash Acquisitions Associated with Better Post-Combination Operating Performance than Stock Acquisitions," Journal of Banking \& Finance, Vol. 25, No. 6, 2001, pp. 1113-1138.

[23] R. Heron and E. Lie, "Operating Performance and the Method of Payment in Takeovers," Journal of Financial and Quantitative Analysis, Vol. 37, No. 1, 2002, pp. 137 155. http://dx.doi.org/10.2307/3594998

[24] K. Gugler, D. Mueller, B. Yurtoglu and C. Zulehner, "The Effects of Mergers: An International Comparison," International Journal of Industrial Organization, Vol. 21, No. 5, 2003, pp. 625-653. http://dx.doi.org/10.1016/S0167-7187(02)00107-8

[25] E. Pamplona and P. R. Junior, "Analysis of Mergers and Acquisitions in Brazilian Companies," African Journal of Business Management, Vol. 7, No. 26, 2013, pp. 26252633.

[26] C. Wang and F. Xie, "Corporate Governance Transfer and Synergistic Gains from Mergers and Acquisitions," Review of Financial Studies, Vol. 22, No. 2, 2009, pp. 829-858.

[27] B. Lau, A. Proimos and S. Wrigth, "Accounting Measures of Operating Performance Outcomes for Australian Mergers," Journal of Applied Accounting Research, Vol. 9, No. 3, 2008, pp. 168-180. http://dx.doi.org/10.1108/09675420810919720

[28] A. Charnes and W. W. Cooper, "Programming with Linear Fractional Functional," Naval Research Logistics Quarterly, Vol. 9, No. 3-4, 1962, pp. 181-185.

[29] M. Tamiz, D. Jones and C. Romero, "Goal Programming for Decision Making: An Overview of the Current StateOf-The-Art," European Journal of Operational Research, Vol. 111, No. 3, 1998, pp. 569-581. http://dx.doi.org/10.1016/S0377-2217(97)00317-2

[30] M. A. Yaghoobi and M. Tamiz, "A Method for Solving Fuzzy Goal Programming Problems Based on MINMAX Approach," European Journal of Operational Research, Vol. 177, No. 3, 2007, pp. 1580-1590. http://dx.doi.org/10.1016/j.ejor.2005.10.022

[31] X.-B. Li and G. Reeves, "A Multiple Criteria Approach to Data Envelopment Analysis," European Journal of Operational Research, Vol. 115, No. 3, 1999, pp. 507-517. http://dx.doi.org/10.1016/S0377-2217(98)00130-1

[32] J. W. M. Bertrand and J. C. Fransoo, "Operations Management Research Methodologies Using Quantitative Modeling," International Journal of Operations \& Production Management, Vol. 22, No. 2, 2002, pp. 241-264. http://dx.doi.org/10.1108/01443570210414338 